\title{
Does Effect From Developmental Methamphetamine Exposure on Spatial Learning and Memory Depend on Stage of Neuroontogeny?
}

\author{
I. HREBÍČKOVÁ ${ }^{1}$, M. ŠEVČÍKOVÁ ${ }^{1}$, K. NOHEJLOVÁ ${ }^{1}$, R. ŠLAMBEROVÁ ${ }^{1}$ \\ ${ }^{1}$ Department of Normal, Pathological and Clinical Physiology, Third Faculty of Medicine, Charles \\ University, Prague, Czech Republic
}

Received March 27, 2016

Accepted October 26, 2016

\section{Summary}

Psychostimulants, including methamphetamine (MA), have neurotoxic effect, especially, if they are targeting CNS during its critical periods of development. The present study was aimed to examine cognitive changes after prenatal and neonatal MA treatment in combination with chronic MA exposure in adulthood of male rats. Eight groups of male rats were tested in adulthood: males whose mothers were exposed to $M A(5 \mathrm{mg} / \mathrm{kg})$ or saline (SA, $1 \mathrm{ml} / \mathrm{kg}$ ) during the first half of gestation period (GD 1-11), the second half of gestation period (GD 12-22) and neonatal period (PD 1-11). In addition, we compared indirect neonatal application via the breast milk with the group of rat pups that received MA or SA directly by injection (PD 1-11). Males were tested in adulthood for cognitive changes in the Morris Water Maze (MWM). MWM experiment lasted for 12 days: Learning (Day 1-6), Probe test (Day 8) and Retrieval Memory test (Day 12). Each day of the MWM animals were injected with MA $(1 \mathrm{mg} / \mathrm{kg})$ or SA $(1 \mathrm{ml} / \mathrm{kg})$. Prenatal MA exposure did not induce changes in learning abilities of male rats, but neonatal exposure to MA leads to an increase search errors and latencies to find the hidden platform. Prenatal and also neonatal MA exposure impaired cognitive ability to remember the position of the platform in Retrieval Memory test in adulthood. Animals exposed to the prenatal treatment within the second half of gestation (ED 12-22) swam longer, slower and spent more time to find the hidden platform in Retrieval Memory test than animals exposed throughout other periods. The present study demonstrated that stage of development is crucial for determination the cognitive deficits induced by prenatal or neonatal MA exposure.

\section{Key words}

Methamphetamine • Trimester • Spatial learning • Memory • Morris Water Maze

\section{Corresponding author}

R. Šlamberová, Department of Normal, Pathological and Clinical Physiology, Third Faculty of Medicine, Charles University, Ke Karlovu 4, 12000 Prague 2, Czech Republic. Fax: +420 224902750. E-mail: romana.slamberova@lf3.cuni.cz

\section{Introduction}

Methamphetamine (MA) is a synthetic derivate of amphetamine, but due to the addition of a methyl group in the chemical structure, it has relatively higher lipid solubility, allowing more rapid transport across the blood-brain barrier (Barr et al. 2002, Rambousek et al. 2014) and has more profound effects on the central nervous system (CNS). In brain, acute administration of MA causes increase in extracellular dopamine (DA) levels via the reverse transport of this monoamine and the displacement from vesicular stores (Sekine et al. 2006). Application of MA may affect also the serotonergic, noradrenergic and glutamatergic systems throughout interactions with serotonin transporters (SERT), dopamine transporters (DAT) and N-methyl-Daspartate (NMDA) receptors (Davis et al. 1992, Šlamberová et al. 2014). Repeated administration of MA decreases striatal DA, 5-HT, their metabolites, DAT and SERT in several brain regions (Ricaurte et al. 1984, Sekine et al. 2006, Wagner et al. 1980). These monoamines have important role in regulation of brain development influencing maturation of dendrites and synaptogenesis (Gaspar et al. 2003, Jablonski et al. 2016, Volkow et al. 2001).

MA is one of the most common drug abused by pregnant women addicted to drug (Marwick 2000); 
it easily crosses a placental and also hematoencephalic barrier of evolving fetus which can result in developmental anomalies, too (Hrubá et al. 2008, Cho et al. 1991). Neuroimaging studies showed anatomical and physiological changes that correlate with functional differences in cognitive function among pups. The study of Chang et al. (2004) demonstrated smaller putamen, globus pallidus and hippocampal volumes in children exposed to MA within gestation. These regional volume reductions correlate with poorer performance in attention and verbal memory. Other study showed reduced caudate nucleus volumes and cortical thickness which were associated with reaction time and behavioral deficits (Derauf et al. 2012, Cho et al. 1991, Šlamberová et al. 2005a,b,c). Developmental MA-exposure leads to decrease connectivity within these DA-rich areas and within the hippocampus, the amygdala, some parts of the cerebellum and medial prefrontal cortex, which are structures important for learning and memory (Rice and Barone 2000, Roussotte et al. 2011, Roussotte et al. 2012). Children, exposed to MA in utero, exhibit impaired learning in a spatial memory task, requiring spatial navigation to a hidden target in a virtual environment (Piper et al. 2011). In animal models of developmental MA effect on cognitive function number studies described correlation between schedule and dose of MA. Acuff-Smith et al. (1996) investigated effect of high dose of MA (15-20 mg/kg) in early days of gestation (ED 7-12), after which were impaired learning and memory of adult rats. Lower doses $(5-10 \mathrm{mg} / \mathrm{kg})$ had no effect on cognition.

Our previous studies demonstrated that prenatal and early neonatal MA exposure has both short- and long-term effects. Administration of MA throughout pregnancy impairs postnatal development of sensorimotor functions in pups during preweaning period (MalinováŠevčíková et al. 2014, Šlamberová et al. 2006, Šlamberová et al. 2005a,b,c), that lasts until adulthood and affects behavior (Šlamberová et al. 2013), anxiety (Šlamberová et al. 2015), cognitive functions (Macúchová et al. 2013), nociception (Yamamotová et al. 2011) and CNS excitability (Bernášková et al. 2011, Matějovská et al. 2014).

Study of Della Grotta et al. (2010) reported that $84.3 \%$ of drug-abusing pregnant women used MA in the first trimester, $56.0 \%$ in the second trimester and $42.4 \%$ continued to use MA during the third trimester. Since regions of the brain mature at different developmental periods it is possible that exposure to MA during these periods will induce certain morphological and functional impairment (Rice and Barone 2000, Williams et al. 2003a, Williams et al. 2003b). The first half of the gestation in rats represents the period of embryonic development; the second half of gestation is the period of organogenesis (Rice and Barone 2000, Rice et al. 2001, Williams et al. 2003a,b). Periods of human embryogenesis and fetogenesis correspond to the rats' development period that is extended from implantation of embryo to approximately three weeks after birth.

Based on the above, we created a rat model of MA exposure during certain stages of prenatal and neonatal development. The developmental differences between rats and humans were taken into account: birth in humans corresponds to the PD 10-12 in rats (Clancy et al. 2007). In order to correspond with the first and the second trimester of pregnancy in humans, rat mothers were administered to MA during the first half (ED 1-11) and the second half (ED 12-22) of their gestation, retrospectively. The third trimester in human corresponds to the early lactation period in rats and therefore MA was administrated also in the period of PD 1-11 (Clancy et al. 2007). Since MA is concentrated and secreted to milk, the sucking pups may receive MA in mother's breast milk (Steiner et al. 1984). Moreover, MA has negative effect on maternal behavior toward pups, which is a major source of tactile stimulation that plays an important role in somatic growth and neural development of their pups (Malinová-Ševčíková et al. 2014, Schanberg and Field 1987, Šlamberová et al. $2005 a, b, c)$. In our study we were interested also in the long-term effect of MA application on cognitive function of exposed offspring via the breast milk. We compared the results with the group that received MA directly by injection, while mothers were discontinued application of MA after birth.

The purpose of the present study was to investigate 1) the effect of prenatal (ED 1-11; ED 12-22) or neonatal (PD 1-11 direct; indirect) MA exposure on cognition in adult male rats, 2) the effect of chronic MA application on spatial learning and memory in adulthood and 3) the effect of period of application (trimesters) on cognitive abilities in adult male rats. In order to test the cognitive deficits, we have used the hidden platform acquisition test in Morris Water Maze (MWM), one of the most widely used task in behavioral neuroscience for study the neural mechanism of spatial learning and memory (Morris et al. 1982). 


\section{Methods}

The procedures used in this study were reviewed and approved by the Institutional Animal Care and Use Committee and they are in agreement with the Czech Government Requirements under the Policy of Humans Care of Laboratory Animals (No. 246/1992) and with the subsequent regulations of the Ministry of Agriculture of the Czech Republic.

\section{Animals}

Adult female (250-300 g) Albino Wistar rats were delivered from Velaz (Prague, Czech Republic, bread by Charles River Laboratories International, Inc.) and housed 4-5 per one cage in temperature-controlled $\left(22-24{ }^{\circ} \mathrm{C}\right)$ colony room with a standard $12 \mathrm{~h}$ light/dark cycle, light on at $06.00 \mathrm{~h}$. After arrival animals were left undisturbed for 1 week with food and water ad libitum. After the acclimation period, the females were weighed and smeared by vaginal lavage to determine the phase of the estrous cycle. Females at the onset of the estrous phase of the estrous cycle were housed overnight with sexually mature males. There was always one female and one male per cage (Šlamberová et al. 2005a,b,c). If the sperms were present in female's vaginal smear on the following day, the fertilization was counted as successful and the day was assigned as Day 1 of gestation (ED 1). Females were randomly assigned to MA-treated (MA) and saline-treated (SA) groups. Physiological saline solution $(0.9 \% \quad \mathrm{NaCl})$ and d-Methamphetamine hydrochloride were purchased from Sigma-Aldrich (Czech Republic).

On the Day 21 of gestation (ED 21), the females were moved from group cages and placed into maternity cages ( 1 female/cage).

A total of 80 litters were used in the present experiment. The number of pups in each litter was adjusted to 12 . Whenever possible, the same number of male and female pups was kept in each litter. To avoid litter bias pups were cross-fostered on postnatal day (PD) 1. One mother usually raised three male and three female pups of her own and three male and three female pups from another mother with the different treatment. In the same time, all prenatally MA-exposed pups were tattooed with black India ink into the left foot and all prenatally SA-exposed pups into the right foot for future identification. Two animals (each with a different prenatal and neonatal exposure) from each litter were used in this study to avoid litter effect (Holson and Pearce
1992). The rest of the animals were used in other studies. On PD 21, pups fostered by MA-treated mothers were ear-punched in the left ear and pups fostered by SA-treated mothers in the right ear for farther identification. After then pups were weaned and housed in groups separated by sex. The light/dark cycle of the animals was reversed with lights on at 06:00. Animals were left undisturbed until adulthood. Only males were tested in the present experiment, females were used in other studies.

\section{Drug administration and experimental groups}

Eight groups of male rats were tested in adulthood: males whose mothers were exposed to MA or saline during the first half of gestation period (GD 1-11), the second half of gestation period (GD 12-22) and neonatal period (PD 1-11). In addition, we compared indirect neonatal application via the breast milk with the group of rat pups that received MA or SA directly by injection (PD 1-11). The dose of MA was $5 \mathrm{mg} / \mathrm{kg} /$ day throughout each period and was administered subcutaneously (s.c.). The dose was chosen based on the findings that this dose of MA administered to pregnant female rats can be transferred across placental membranes as well as into breast milk and corresponds to the levels found in plasma and brain of the fetuses of drug-abusing women (Acuff-Smith et al. 1996, Rambousek et al. 2014, Šlamberová et al. 2005a,b,c). The females from the control groups were administered saline $(\mathrm{SA}, 1 \mathrm{ml} / \mathrm{kg})$ at the same time and in the same volume as MA (Table 1). The dose was chosen based on the findings that this dose of MA administered to pregnant female rats corresponds to the levels found in the fetuses of drug-abusing women (Acuff-Smith et al. 1996, Šlamberová et al. 2006). Based on the prenatal/ neonatal exposure and adult treatment there were fourtesting groups for each injection period: $\mathrm{SA} / \mathrm{SA}=$ prenatal/neonatal saline exposure and adult saline treatment; $\mathrm{SA} / \mathrm{MA}=$ prenatal/neonatal saline exposure and adult methamphetamine treatment; $\mathrm{MA} / \mathrm{SA}=$ prenatal/neonatal methamphetamine exposure and adult saline treatment; $\mathrm{MA} / \mathrm{MA}=$ prenatal/neonatal methamphetamine exposure and adult methamphetamine treatment.

\section{Morris Water Maze test}

The male offspring ( $\mathrm{n}=8$, Table 1$)$ were tested in adulthood (PD 60-90) for learning and memory in the MWM (Schutová et al. 2008). The MWM tests had three 
phases: Place Navigation test (Learning) on Days 1-6, Probe test on Day 8 and Memory Retention test (Memory) on Day 12. During these subsequent 12 days animals received chronic treatment with MA $(1 \mathrm{mg} / \mathrm{kg})$ or SA $(1 \mathrm{ml} / \mathrm{kg})$; each day of testing in the swimming pool were treated immediately after swimming, in other days of the MWM test were treated in the same time as in days of swimming. The low dose of MA was chosen because it does not lead to stereotypes that could affect swimming, unlike the higher dose of $5 \mathrm{mg} / \mathrm{kg}$ used during gestation (Šlamberová et al. 2006).

Table 1. Assignment of the animals to individual groups according to the schedule and the type of prenatal (ED 1-11 or ED 12-22) and neonatal (PD 1-11 direct and indirect) treatment versus acute application in adulthood.

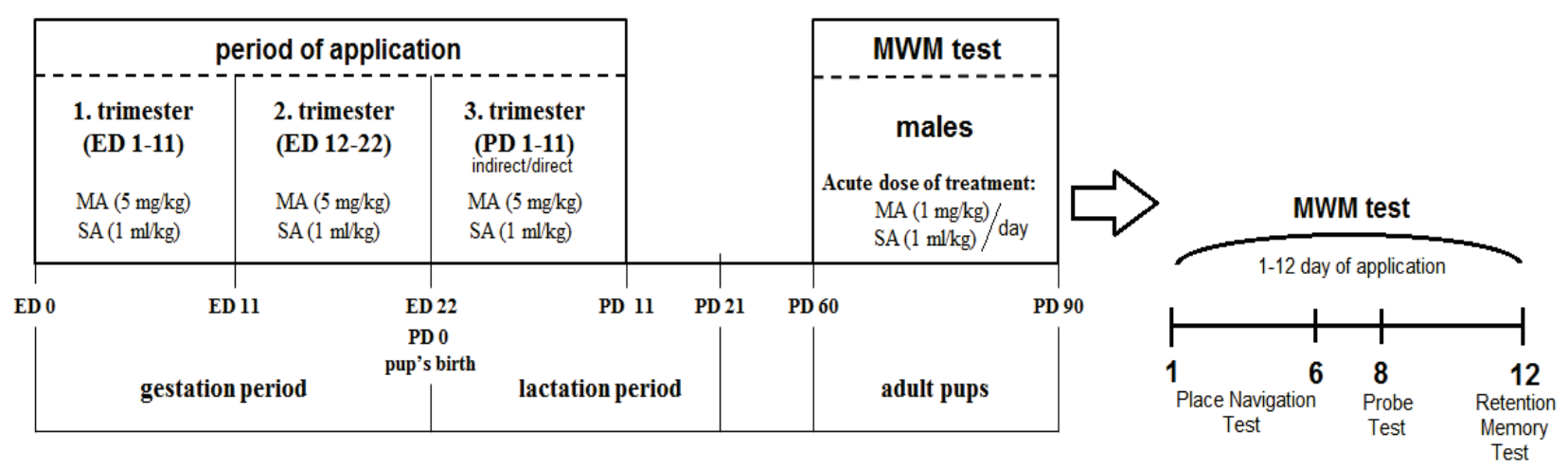

Total number of male rats used in experiment was 128; individual group accounted: 8 animals. Adult long-term treatment started on the day of beginning of MWM tests and continues for subsequent 12 days. The MA dose of $5 \mathrm{mg} / \mathrm{kg}$ was used during gestation and early lactation period and $1 \mathrm{mg} / \mathrm{kg}$ was used for chronic application in adulthood (Šlamberová et al. 2006).

The Place Navigation test of hidden platform acquisition was chosen to evaluate spatial learning. The platform was placed in stable position $1 \mathrm{~cm}$ under the water surface, invisible for the swimming rats. Four starting positions were assigned on the rim of the maze: north $(\mathrm{N})$, south $(\mathrm{S})$, east $(\mathrm{E})$, west $(\mathrm{W})$, dividing the maze into four quadrants, where platform was placed in N-E quadrant. Various pictures were hanging on the walls and could be used by rats as extra-maze cues. The Place Navigation test was performed during 6 days of the experiment. An animal was expected to find the platform within the limit of $60 \mathrm{~s}$. If the animal was not able to found platform as assigned, it was manually guided to the platform, where it remained for $30 \mathrm{~s}$. Each rat performed 8 trials daily starting from 4 different positions with $30 \mathrm{~s}$ intervals in between. Rats' performance was tracked automatically using a video-tracking system EthoVision XT7 (Noldus Information Technology, The Netherlands). The following parameters were evaluated: latency to reach the hidden platform [s], distance traveled [cm], search error [cm] (a measure of proximity to the escape platform though the trial) and velocity of swimming $[\mathrm{cm} / \mathrm{s}]$. After finishing all trials in the experimental day, animal was dried by towel and injected either by MA $(1 \mathrm{mg} / \mathrm{kg})$ or $\mathrm{SA}(1 \mathrm{ml} / \mathrm{kg})$ according to the group assigned (Table 1). Thereafter animal was returned to its home cage and remained undisturbed till the next experiment day.

In the Probe test, which was conducted on the $8^{\text {th }}$ day of the experiment, the platform was removed and the animal was left to swim in the maze for $60 \mathrm{~s}$. The start position was north $(\mathrm{N})$, which is the nearest location to previous platform position. The following parameters were recorded: distance travelled $[\mathrm{cm}]$, the velocity of swimming $[\mathrm{cm} / \mathrm{s}]$, number of crossing of the former position of the platform, number of crossing and the duration of presence in the quadrant where the platform was located [s], number of crossing and the duration of presence in the opposite quadrant [s].

The Memory Retention test was performed on the $12^{\text {th }}$ day of the experiment and the rat supposed to find the platform located in the same position as in the learning phase within $60 \mathrm{~s}$. Each rat was performed to 8 trials starting from four different positions. The following parameters were evaluated: latency to reach the hidden platform [s], distance traveled [cm], search error $[\mathrm{cm}]$ and velocity of swimming $[\mathrm{cm} / \mathrm{s}]$.

\section{Statistical analyses}

Effect of MA treatment

Two-way ANOVA (Prenatal exposure $x$ Treatment in adulthood) with multilevel repeated 
measure (Days $x$ Trials/day) was used to analyze the data from the Place Navigation test. Two-way ANOVA (Prenatal exposure $x$ Treatment in adulthood) was used to analyze the data from the Probe test. Two-way ANOVA (Prenatal exposure $x$ Treatment in adulthood) with repeated measure (Trials) was used to analyze the data from the Retention Memory test.

\section{Effect of application period (Trimester)}

Because our results suggested that there might be differences induced by application of MA in different periods that correspond to human trimesters, we decided to run additional statistical analysis that would compare results between the individual testing periods (ED 1-11, ED 12-22, PD 1-11 - mothers exposed; indirect effect and PD 1-11 - pups exposed; direct effect). A Three-way ANOVA (Prenatal or Neonatal exposure $x$ Treatment in adulthood $x$ Trimester) with repeated measure (Trials) was further used to analyze the data from the MWM test. Differences were considered significant in all statistical analyses if $\mathrm{p}<0.05$.
A. ED 1-11

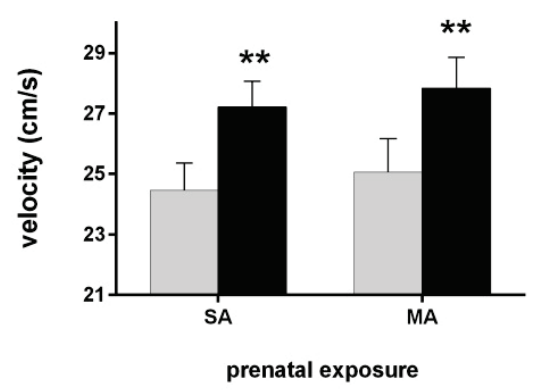

C. PD 1-11 indirect

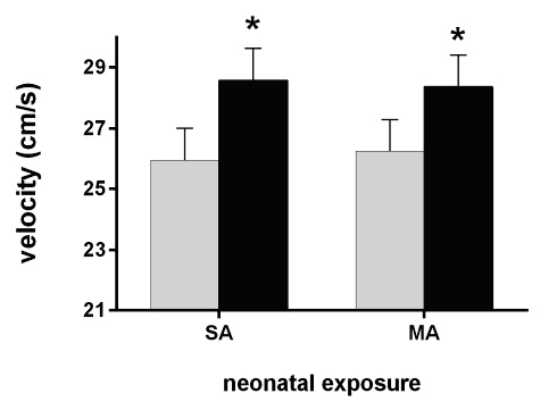

B. ED 12-22

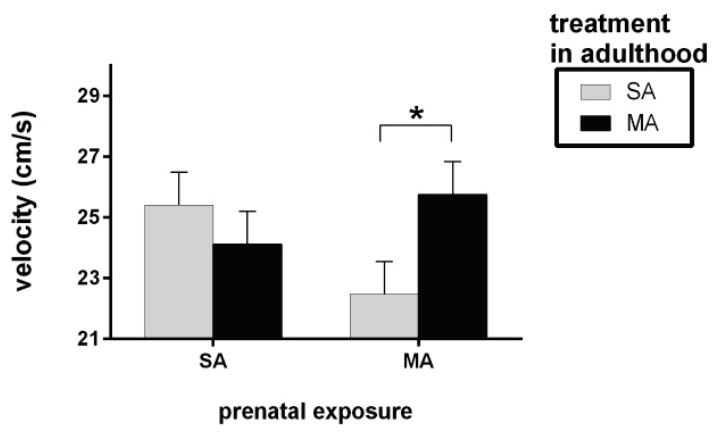

D. PD 1-11 direct

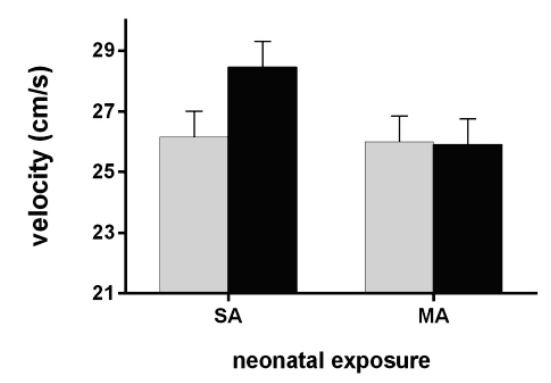

Fig. 1. Effect of prenatal, neonatal and adult MA exposure on velocity of swimming in the Place Navigation test. Results are presented as mean \pm SEM, $n=8$. A. ED 1-11. $* * p<0.01$ - main effect of chronic MA treatment in adulthood: MA groups swam faster than SA-treated animals. B. ED 12-22. * $p<0.05-$ MA/MA $>$ MA/SA. C. PD 1-11 indirect. * $p<0.05-$ main effect of chronic MA application in adulthood: MA group vs. SA group. D. PD 1-11 direct.

\section{Results}

\section{Place Navigation test}

ED 1-11: In the group of adult male rats exposed in ED 1-11, neither prenatal MA exposure nor MA treatment in adulthood affected the latencies $[\mathrm{F}(5,135)=1.12 ; \quad \mathrm{p}=0.36], \quad$ the distances traveled $[F(5,140)=1.47 ; \quad p=0.20]$ and the search errors $[F(5,140)=0.80 ; p=0.55]$ in Place Navigation test. The only difference was found in the velocity to reach the hidden platform (Fig. 1A). MA treatment in adulthood increased the velocity of swimming when compared to
SA-treated controls and this effect was independent on the prenatal drug exposure $[\mathrm{F}(1,28)=8.02 ; \mathrm{p}<0.01]$.

ED 12-22: In the group of adult male rats exposed in ED 12-22, there were no differences between groups in the latency $[\mathrm{F}(5,140)=2.27 ; \mathrm{p}=0.07]$, the distance traveled $[\mathrm{F}(5,140)=2.72 ; \mathrm{p}=0.06]$ or the search error $[F(5,140)=2.24 ; p=0.07]$. On the other hand, the velocity of swimming (Fig. 1B) was increased by adult MA treatment, but only in prenatally MA-exposed and not in prenatally SA-exposed animals $[\mathrm{F}(1,28)=4.47$; $\mathrm{p}<0.05]$.

PD 1-11 (indirect): Neither MA exposure via the 
breast milk nor chronic MA application in adulthood induce changes in the latency $[\mathrm{F}(1,28)=4.31 ; \mathrm{p}=0.53]$ and in the search error $[F(1,28)=3.65 ; p=0.06]$. In the distance traveled there was an effect of neonatal MA exposure, where rats exposed to MA with SA treatment in adulthood (MA/SA) swam longer distance than rats exposed to neonatal SA (SA/SA) $[\mathrm{F}(1,28)=9.08$; $\mathrm{p}<0.01]$. Chronic MA application in adulthood increased the velocity of swimming in both, SA and MA neonatally exposed groups $[F(1,28)=5.09 ; p<0.05]$ (Fig. 1C).

PD 1-11 (direct): Rats exposed to MA by direct injection to pups displayed higher latency $[\mathrm{F}(1,28)=4.41$; $\mathrm{p}<0.05]$ and higher search error $[\mathrm{F}(1,28)=4.21 ; \mathrm{p}<0.05]$ than rats exposed to SA regardless of chronic treatment in adulthood. Neither neonatal, nor chronic application of drug affected the distance traveled $[\mathrm{F}(1,28)=1.06$; $\mathrm{p}=0.31]$ and the velocity of swimming $[\mathrm{F}(1,28)=1.95$; $\mathrm{p}=0.17]$ (Fig. 1D).

\section{Probe test}

ED 1-11: In the group of adult male rats exposed in ED 1-11, neither prenatal MA exposure, nor adult MA treatment changed the performance of the Probe test.

ED 12-22: In the group of adult male rats exposed in ED 12-22, there was an interaction between prenatal exposure and adult treatment in the velocity $[\mathrm{F}(1,28)=4.91 ; \mathrm{p}<0.05]$ and in distance traveled $[\mathrm{F}(1,28)=4.97 ; \mathrm{p}<0.05]$. Animals prenatally exposed to MA and treated in adulthood with SA (MA/SA) swam slower and swam shorter distance than prenatally SA-exposed rats treated in adulthood with SA (SA/SA) or prenatally MA-exposed rats treated in adulthood with MA (MA/MA). However, as a matter the number of crossing of former platform placement or swimming in correct or incorrect quadrant, there were no statistical differences.

PD 1-11 (indirect): MA treatment in adulthood increased the velocity of swimming $[\mathrm{F}(1,28)=13.82$; $\mathrm{p}<0.001]$ regardless of indirect neonatal exposure via the breast milk. Neonatal or chronic application in adulthood did not affect the other tested parameters in Probe test.

PD 1-11 (direct): Males treated neonatally with direct exposure and in adulthood with MA (MA/MA) spent less time to find the hidden platform in zone quadrant opposite to the location of platform $[F(1,28)=4.37 ; p<0.05]$, but there were no changes in the latency in zone quadrant, where the platform was placed $[F(1,28)=6.40 ; p=0.34]$.

\section{Retention Memory test}

ED 1-11: In the group of adult male rats exposed in ED 1-11, there were no significant differences induced by prenatal exposure or adult treatment in the latency $[F(7,196)=0.68 ; p=0.69]$ (Fig. 2A), the distance traveled $[F(7,196)=0.62 ; p=0.74] \quad$ (Fig. 3A), the search error $[F(7,196)=0.47 ; p=0.86]$ or the velocity $[F(7,196)=0.42$; $\mathrm{p}=0.89]$.

ED 12-22: In the group of adult male rats exposed in ED 12-22, there was an interaction between prenatal exposure and adult treatment in the latency $[F(1,28)=4.47 ; p<0.05]$ (Fig. 2B), the distance traveled $[F(1,28)=7.97 ; p<0.01]$ (Fig. $3 B$ ) and the search error $[\mathrm{F}(1,28)=4.35 ; \mathrm{p}<0.05]$. Prenatally SA-exposed animals with adult MA treatment (SA/MA) had shorter latencies, swam shorter distance and did less search errors than prenatally SA-exposed rats treated in adulthood with SA (SA/SA). Moreover, prenatally MA-exposed animals treated in adulthood with SA (MA/SA) swam shorter distance than prenatally SA-exposed animals with adult SA treatment $(\mathrm{SA} / \mathrm{SA})[\mathrm{F}(1,28)=7.97 ; \mathrm{p}<0.05]$. The velocity of swimming was not changed in the Retention Memory test $[\mathrm{F}(7,196)=1.40 ; \mathrm{p}=0.21]$.

PD 1-11 (indirect): In the group of adult male rats exposed in PD 1-11 indirectly via the breast milk, neither neonatal MA exposure, nor MA application in adulthood changed the latency $[\mathrm{F}(1,28)=0.75 ; \mathrm{p}=0.40]$ (Fig. $2 \mathrm{C}$ ), the distance traveled $[F(1,28)=3.50 ; p=0.07]$ (Fig. 3C), the search error $[\mathrm{F}(1,28)=0.47 ; \mathrm{p}=0.50]$, and velocity $[F(1,28)=0.23 ; p=0.64]$ in the Retention Memory test.

PD 1-11 (direct): In the group of adult male rats with direct injections in PD 1-11, neither neonatal MA exposure, nor adult MA treatment changed the performance of the Retention Memory test: the latency $[F(1,28)=2.16 ; p=0.15]$ (Fig. 2D), the distance traveled $[F(1,28)=5.60 ; p=0.25]$ (Fig. 3D), the search error $[\mathrm{F}(1,28)=4.04 ; \mathrm{p}=0.60]$, and velocity $[\mathrm{F}(1,28)=1.27$; $\mathrm{p}=0.27]$.

\section{Effect of application period (Trimester)}

As shown in Figure 4, animals exposed to the prenatal treatment within the second half of gestation had longer latencies $[\mathrm{F}(1,56)=11.99 ; \mathrm{p}<0.01](\mathrm{A})$, swam longer distances $[\mathrm{F}(1,56)=4.63 ; \mathrm{p}<0.05](\mathrm{B})$, displayed worse search errors $[\mathrm{F}(1,56)=14.67 ; \mathrm{p}<0.01](\mathrm{C})$ and swam slower $[F(1,56)=7.48 ; \mathrm{p}<0.01]$ (D) than animals exposed to the prenatal treatment within the first half of gestation and within early neonatal period exposed indirectly via the breast milk or directly by application of injection. 
A. ED 1-11

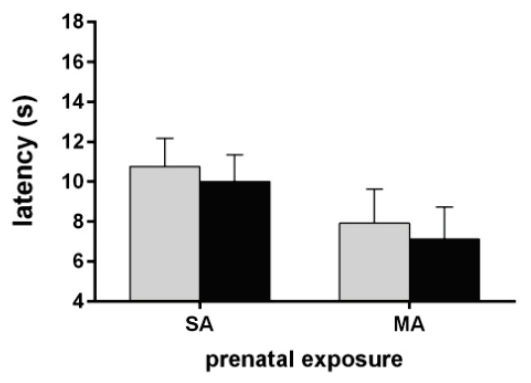

C. PD 1-11 indirect

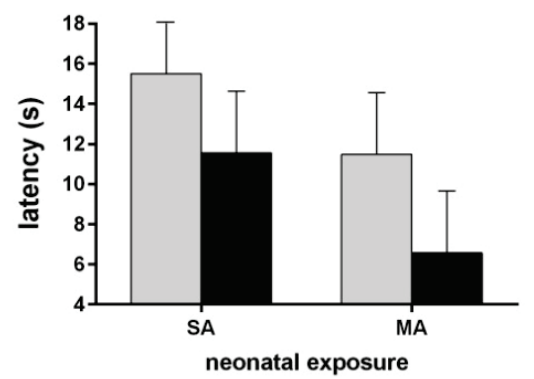

B. ED 12-22

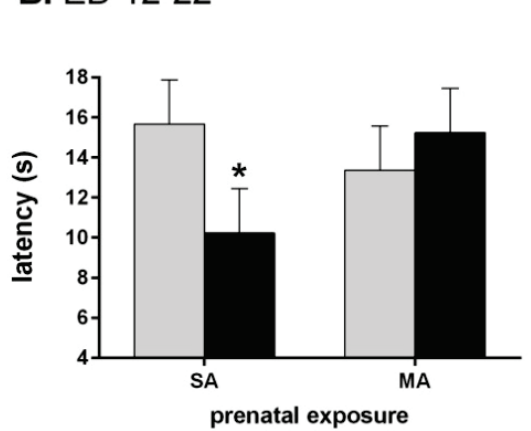

D. PD 1-11 direct

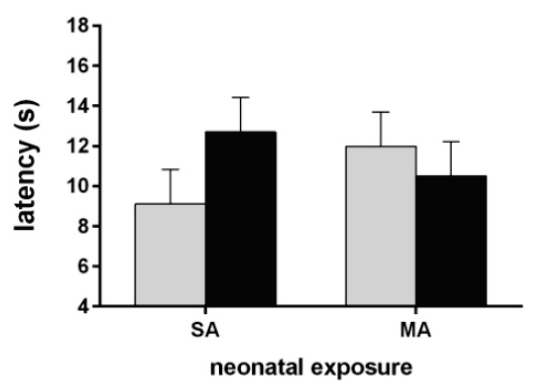

Fig. 2. Effect of prenatal, neonatal and adult $M A$ exposure on the latency of platform acquisition in the Retention Memory test. Results are presented as mean $\pm \mathrm{SEM}, \mathrm{n}=8$. A. ED 1-11. B. ED 12-22. * $\mathrm{p}<0.05$ - main effect of chronic MA application in groups prenatally exposed to SA (SA/SA vs. SA/MA). C. PD 1-11 indirect. D. PD 1-11 direct.

\section{A. ED 1-11}

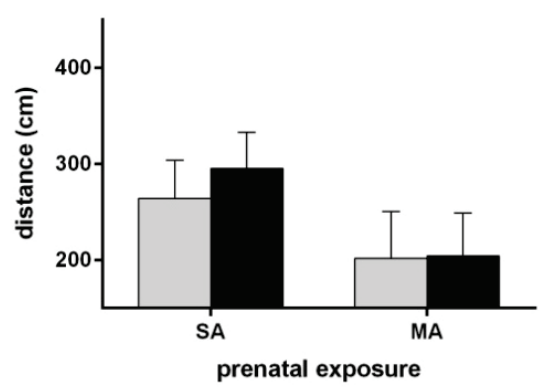

C. PD 1-11 indirect

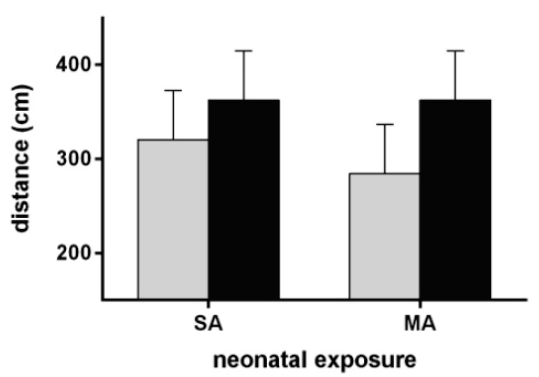

B. ED 12-22

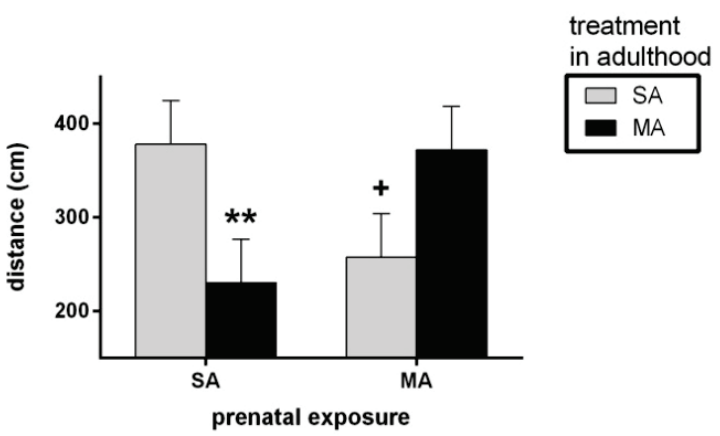

D. PD 1-11 direct

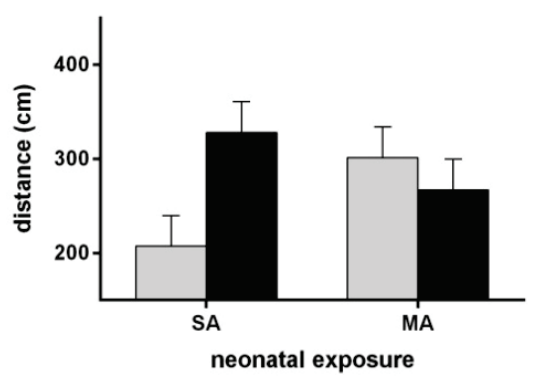

Fig. 3. Effect of prenatal, neonatal and adult MA exposure on the distance traveled in Retention Memory test. Results are presented as mean $\pm S E M, n=8$. A. ED 1-11. B. ED 12-22. $* * p<0.01-$ main effect of chronic MA application in groups prenatally exposed to SA $(\mathrm{SA} / \mathrm{SA}<\mathrm{SA} / \mathrm{MA}) .+\mathrm{p}<0.05$ effect of prenatal $\mathrm{MA}$ exposure in compare to prenatal SA after acute SA treatment in adulthood $(\mathrm{MA} / \mathrm{SA}<\mathrm{SA} / \mathrm{SA})$. C. PD 1-11 indirect. D. PD 1-11 direct. 
A.

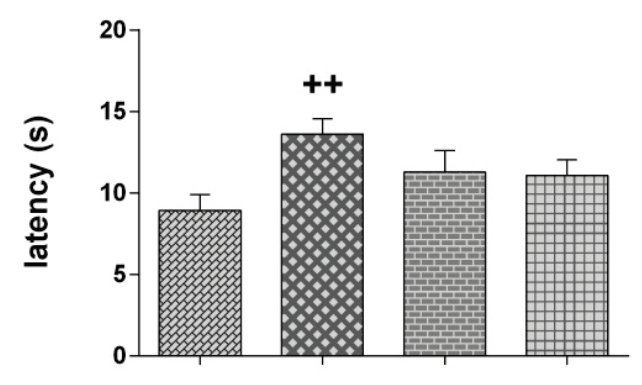

C.

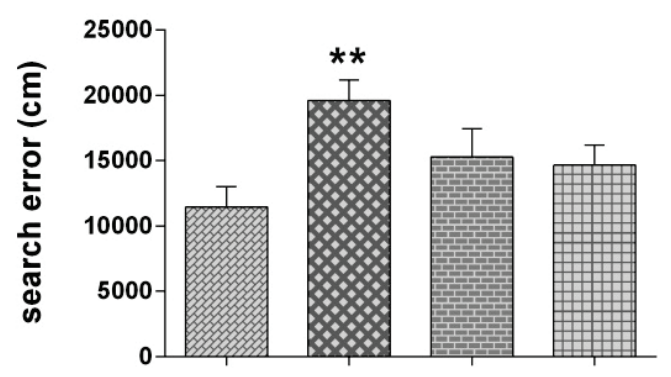

B.

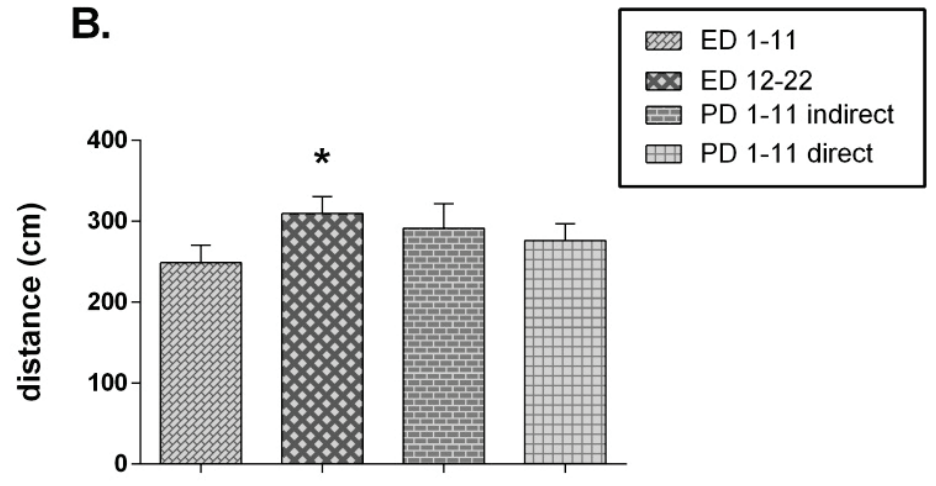

D.

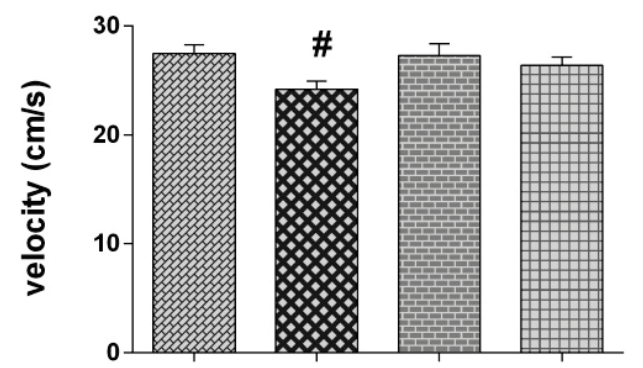

Fig. 4. Effect of prenatal, neonatal and chronic exposure on performance in the Memory Retention test. Results are presented as an average of all groups in each of the injection schedules, mean $\pm S E M, n=32$. A. Latency of platform acquisition. $++p<0.01-$ rats exposed in ED 12-22 spent more time to find the hidden platform than rats exposed in other periods. B. Distance traveled. $* \mathrm{p}<0.05-$ rats exposed in ED 12-22 swam longer distances than rats exposed in ED 1-11. C. Search error. ** $p<0.01-$ rats exposed within ED 12-22 displayed worse search errors than rats exposed in other periods. D. Velocity of swimming. \# $\mathrm{p}<0.05-$ rats exposed in ED 12-22 swam slower than rats exposed in other periods.

\section{Discussion}

The aim of the present study was to examine the effect of MA treatment in adulthood $(1 \mathrm{mg} / \mathrm{kg})$ on cognitive function of adult male rats exposed to the same drug $(5 \mathrm{mg} / \mathrm{kg})$ throughout different stages of the CNS development.

First, this study indicates that prenatal MA exposure within both gestational periods (ED 1-11, ED 12-22) that correspond to the first and the second human trimester did not affect the latency, the search error and the length of the trajectory in the Place Navigation test (test of learning). These results are in agreements with our previous studies (Macúchová et al. 2013, Macúchová et al. 2014, Schutová et al. 2008, Schutová et al. 2009, Šlamberová et al. 2014), in which prenatal MA exposure throughout the entire gestation at a dose $5 \mathrm{mg} / \mathrm{kg}$ did not influence the learning ability in both males and females in the MWM. Also other studies showed, that prenatal MA exposure did not alter changes in spatial navigation following longer exposure periods (one week prior to mating and throughout gestation) (McDonnell-Dowling et al. 2014) or using lower or higher doses of MA $(0.625-10 \mathrm{mg} / \mathrm{kg} /$ day) (Weissman and Caldecott-Hazard 1995).

On the other hand, rats exposed to MA within the third human trimester (PD 1-11) by application of injection (direct exposure) displayed longer latencies and did more search errors to find the hidden platform than rats exposed to neonatal SA. Also indirect neonatal MA exposure via the breast milk resulted in learning impairment, where adult rats swam longer distances to the hidden platform than control animals. Our data correspond with results of other (Schaefer et al. 2008) showing that MA in dose $10 \mathrm{mg} / \mathrm{kg}$ administered 4 times per day between PD 11-20 produces spatial learning deficits in the MWM. On the other hand, Vorhees (1997) reported that higher doses of MA $(30 \mathrm{mg} / \mathrm{kg} 2$ times per day) administered to rats from PD 11-20 showed increased latencies to find the hidden and moved 
platform, but when the same dose of MA was administered between PD 1-10 it did not induce such differences. Thus, our results and the results of others (Schaefer et al. 2008, Vorhees 1997) suggest that the effect of MA administered during the early postnatal period depends on the dose and the timing of exposure.

The Probe test is a good way of analysis of the memory recall quality during which is the escape platform removed. In the present study only animals prenatally exposed to MA throughout ED 12-22 displayed better performance in the Probe test, the way that MA-exposed males swam shorter distances than males exposed to prenatal SA. Similarly, to the present results our previous study of Schutová et al. (2009) showed that prenatal MA exposure improves performance in the Retention Memory test in the MWM. The difference of our present and previous effects might be in the length of prenatal MA exposure or in the fact that Schutová et al. (2009) tested the Probe test in the $6^{\text {th }}$ day of the experiment, while in the present study it was on day 8 .

Second, the effect of MA application in adulthood showed increased velocity of swimming in all animals regardless of prenatal or neonatal exposure during the Place Navigation test. In the Probe test and Retention Memory test, there was no effect on velocity of swimming of rats treated with MA in adulthood. These results suggest that MA application in adulthood increased the motivation of the animals to find the hidden platform during the first phase of MWM test (the Place Navigation test), when the hidden platform is a new, interesting object for rats, while during the Probe test and Retention Memory test, the rats might be already less interested for searching the hidden platform (Lubbers et al. 2007). This hypothesis is supported by finding that the differences in velocity between MA and SA groups decreases as the 6-day learning progress (data not shown).

Other possibility how to explain increased speed of swimming of rats treated with MA in adulthood might be MA-induced locomotion per se. There are studies that would support this hypothesis (Bisagno et al. 2003, Gentry et al. 2004). However, it should be noted that animals were tested daily not earlier than $23 \mathrm{~h}$ after MA application (MA was injected always at the end of each trial), thus the acute effect of MA at the time of next-day swimming already disappeared. Moreover, the finding that the increase of swimming velocity was seen only during the Place Navigation test, but not during the Probe test and Retention Memory test seems to be unreasonable and thus it does not support this hypothesis. Therefore, the above mentioned increased motivation seems to better explanation for the differences in the velocity. Motivation is assumed to be mediated by meso-accumbens dopamine system (Nocjar and Panksepp 2002, Robinson and Becker 1986, Robinson and Kolb 2004, Salamone and Correa 2002) and this system had been shown to be altered by adult MA application.

In the Retention Memory test the effect of chronic MA application in adulthood in rats exposed to prenatal SA during the second trimester (ED 12-22) was found. This group (SA/MA) had significantly shorter latencies, swam shorter distances and had lower search errors. These results suggest that animals with MA treatment in adulthood memorized the location of the platform most accurately (Hrebíčková et al. 2014). Thus, the second trimester (ED 12-22) seems to be the most sensitive period of neurogenesis for the effect of MA application.

Third, MA exposure during different stages of gravidity leads to a range of physiological and anatomical abnormalities in brain structures (Rice and Barone 2000, Williams et al. 2003a,b). Our previous studies examined the effect of MA exposure throughout the entire prenatal period on learning and memory in the MWM (Macúchová et al. 2013, Schutová et al. 2009).

This period of brain development (ED 1-22) corresponds to the first (ED 1-11) and the second (ED 12-22) human trimester equivalents, during which organogenesis, neurulation and histogenesis in brain had occurred rapidly on ED 9 (Fentress 1988, Kelley and Berridge 2002). Neuronal proliferation, migration, cell differentiation, synaptogenesis and gliogenesis begin expand rapidly from ED 10 (Nocjar and Panksepp 2002, Rice and Barone 2000). MA exposure during this periods leads to a range of anatomical abnormalities (AcuffSmith et al. 1996, Cho et al. 1991, Melo et al. 2006, Melo et al. 2008). Regional neurogenesis starts to develop in medulla, pons, thalamus, hypothalamus, hippocampal sub-region and some part of cerebellum between ED 12 to the first days of postnatal period of rats (Bayer et al. 1993, Jablonski et al. 2016, Rice and Barone 2000). Targeting one or more of these developing brain regions can cause cognitive deficits based on abnormalities in these structures (Jablonski et al. 2016, Won et al. 2001).

The neonatal period of rat brain development (PD 1-12) is analogous to human brain development 
during the end of the second trimester and during the third trimester, depending upon the region (Rice and Barone 2000). Brain regions that mediate higher cognitive function are developing during this sensitive period (Jablonski et al. 2016). There is a substantial increase in the proliferation of glial cells, hippocampal neurogenesis, synaptogenesis and dendritic arborization, rapid increases in neurotransmitter system and associated receptor expression (DAT, SERT) (Bayer et al. 1993, Herlenius and Lagercrantz 2004, Jablonski et al. 2016). MA exposure within these periods disrupts neuronal populations and leads to functional changes in disabled structures which can results in impairments in spatial learning and memory (Bayer et al. 1993, Jablonski et al. 2016).

Since regions of the brain mature in different rates it is possible that exposure to the drugs may produce effects during one developmental time period, but not another. Rat hippocampus, a brain structure responsible for spatial learning and memory, begins to develop on ED 14 and continues until PD 19 (Bayer et al. 1993). Our results demonstrated that animals exposed to the prenatal treatment during the second trimester (ED 12-22) had significantly longer latencies, swam longer distances, swam slower and displayed more search errors than animals exposed within others trimesters. Based on our results, this period (ED 12-22) seems to be a more sensitive for effect of MA than other periods of neurogenesis.

In conclusion, the present study demonstrates that the stage of the prenatal or early neonatal development seems to be crucial for drug administration and its effects on cognitive functions. Our data suggest that neonatal MA exposure (PD 1-11) that corresponds to human third trimester is the only period affecting spatial learning in the MWM, while the second trimester (ED 12-22) is crucial to induce sensitization for drug administration in adulthood. Based on our data, it seems that MA exposure affects development of hippocampal monoaminergic nerve terminals that mostly develop during late gestation and early neonatal period of rat neurogenesis.

\section{Conflict of Interest}

There is no conflict of interest.

\section{Acknowledgements}

This study was supported by grant \# GA 14-03708S from Grant Agency of the Czech Republic, and projects \# PRVOUK P34, GAUK 706216 and 260277/SVV/2016 from Charles University.

\section{References}

ACUFF-SMITH K, GEORGE M, LORENS S, VORHEES C: Preliminary evidence for methamphetamine-induced behavioral and ocular effects in rat offspring following exposure during early organogenesis. Psychopharmacology 109: 255-263, 1996.

BARR AM, MARKOU A, PHILLIPS AG: A 'crash' course on psychostimulant withdrawal as a model of depression. Trends Pharmacol Sci 23: 475-482, 2002.

BAYER SA, ALTMAN J, RUSSO RJ, ZHANG X: Timetables of neurogenesis in the human brain based on experimentally determined patterns in the rat. Neurotoxicology 14: 83-144, 1993.

BERNÁŠKOVÁ K, MATĚJOVSKÁ I, ŠLAMBEROVÁ R: Postnatal challenge dose of methamphetamine amplifies anticonvulsant effects of prenatal methamphetamine exposure on epileptiform activity induced by electrical stimulation in adult male rats. Exp Neurol 229: 282-287, 2011.

BISAGNO V, FERGUSON D, LUINE VN: Chronic D-amphetamine induces sexually dimorphic effects on locomotion, recognition memory, and brain monoamines. Pharmacol Biochem Behav 74: 859-867, 2003.

CHANG L, SMITH LM, LOPRESTI C, YONEKURA ML, KUO J, WALOT I, ERNST T: Smaller subcortical volumes and cognitive deficits in children with prenatal methamphetamine exposure. Psychiatry Res 132: 95-106, 2004.

CHO D, LYU H, LEE H, KIM P, CHIN K: Behavioral teratogenity of methamphetamine. J Toxicol Sci 16: 37-49, 1991.

CLANCY B, FINLAY BL, DARLINGTON RB, ANAND KJ: Extrapolating brain development from experimental species to humans. Neurotoxicology 28: 931-937, 2007. 
DAVIS S, BUTCHER SP, MORRIS RGM: The NMDA receptor antagonist D-2-amino-5-phosphonopentanoate (D-AP5) impairs spatial-learning and LTP in vivo at intracerebral concentrations comparable to those that block LTP in vitro. $J$ Neurosci 12: 21-34, 1992.

DELla GROTTA S, LAGASSE LL, ARRIA AM, DERAUF C, GRANT P, SMITH LM, SHAH R, HUESTIS M, LIU J, LESTER BM: Patterns of methamphetamine use during pregnancy: results from the Infant Development, Environment, and Lifestyle (IDEAL) Study. Matern Child Health J 14: 519-527, 2010.

DERAUF C, LAGASSE LL, SMITH LM, NEWMAN E, SHAH R, NEAL CR, ARRIA AM, HUESTIS MA, DELlaGROTTA S, DANSEREAU LM, LIN H, LESTER BM: Prenatal methamphetamine exposure and inhibitory control among young school-age children. J Pediatr 161: 452-459, 2012.

FENTRESS JC: Expressive contexts, fine structure, and central mediation of rodent grooming. Ann N Y Acad Sci 525: 18-26, 1988.

GASPAR P, CASES O, MAROTEAUX L: The developmental role of serotonin: news from mouse molecular genetics. Nat Rev Neurosci 4: 1002-1012, 2003.

GENTRY WB, GHAFOOR AU, WESSINGER WD, LAURENZANA EM, HENDRICKSON HP, OWENS SM: $(+)$-Methamphetamine-induced spontaneous behavior in rats depends on route of $(+) \mathrm{METH}$ administration. Pharmacol Biochem Behav 79: 751-760, 2004.

HERLENIUS E, LAGERCRANTZ H: Development of neurotransmitter systems during critical periods. Exp Neurol 190 (Suppl 1): S8-S21, 2004.

HOLSON RR, PEARCE B: Principles and pitfalls in the analysis of prenatal treatment effects in multiparous species. Neurotoxicol Teratol 14: 221-228, 1992.

HREBÍČKOVÁ I, MALINOVÁ-ŠEVČÍKOVÁ M, MACÚCHOVÁ E, NOHEJLOVÁ K, ŠLAMBEROVÁ R: Exposure to methamphetamine during first and second half of prenatal period and its consequences on cognition after long-term application in adulthood. Physiol Res 63 (Suppl 4): S535-S545, 2014.

HRUBÁ L, SCHUTOVÁ B, ŠLAMBEROVÁ R, POMETLOVÁ M: Does cross-fostering modify the impairing effect of methamphetamine on postnatal development of rat pups? Prague Med Rep 109: 50-61, 2008.

JABLONSKI SA, WILLIAMS MT, VORHEES CV: Neurobehavioral effects from developmental methamphetamine exposure. Curr Top Behav Neurosci 29: 183-230, 2016.

KELLEY AE, BERRIDGE KC: The neuroscience of natural rewards: relevance to addictive drugs. J Neurosci 22 : 3306-3311, 2002.

LUBBERS ME, VAN DEN BOS R, SPRUIJT BM: Mu opioid receptor knockout mice in the Morris Water Maze: a learning or motivation deficit? Behav Brain Res 180: 107-111, 2007.

MACÚCHOVÁ E, NOHEJLOVÁ-DEYKUN K, ŠLAMBEROVÁ R: Effect of methamphetamine on cognitive functions of adult female rats prenatally exposed to the same drug. Physiol Res 62 (Suppl 1): S89-S98, 2013.

MACÚCHOVÁ E, NOHEJLOVÁ K, ŠLAMBEROVÁ R: Gender differences in the effect of adult amphetamine on cognitive functions of rats prenatally exposed to methamphetamine. Behav Brain Res 270: 8-17, 2014.

MALINOVÁ-ŠEVČÍKOVÁ M, HREBÍČKOVÁ I, MACÚCHOVÁ E, NOVÁ E, POMETLOVÁ M, ŠLAMBEROVÁ $\mathrm{R}$ : Differences in maternal behavior and development of their pups depend on the time of methamphetamine exposure during gestation period. Physiol Res 63 (Suppl 4): S559-S572, 2014.

MARWICK C: NIDA seeking data on effect of fetal exposure to methamphetamine. JAMA 283: 2225-2226, 2000.

MATĚJOVSKÁ I, BERNÁŠKOVÁ K, ŠLAMBEROVÁ R: Effect of prenatal methamphetamine exposure and challenge dose of the same drug in adulthood on epileptiform activity induced by electrical stimulation in female rats. Neuroscience 257: 130-138, 2014.

MCDONNELL-DOWLING K, DONLON M, KELLY JP: Methamphetamine exposure during pregnancy at pharmacological doses produces neurodevelopmental and behavioural effects in rat offspring. Int $J$ Dev Neurosci 35: 42-51, 2014.

MELO P, MORENO VZ, VAZQUEZ SP, PINAZO-DURAN MD, TAVARES MA: Myelination changes in the rat optic nerve after prenatal exposure to methamphetamine. Brain Res 1106: 21-29, 2006.

MELO P, PINAZO-DURAN MD, SALGADO-BORGES J, TAVARES MA: Correlation of axon size and myelin occupancy in rats prenatally exposed to methamphetamine. Brain Res 1222: 61-68, 2008. 
MORRIS RG, GARRUD P, RAWLINS JN, O'KEEFE J: Place navigation impaired in rats with hippocampal lesions. Nature 297: 681-683, 1982.

NOCJAR C, PANKSEPP J: Chronic intermittent amphetamine pretreatment enhances future appetitive behavior for drug- and natural-reward: interaction with environmental variables. Behav Brain Res 128: 189-203, 2002.

PIPER BJ, ACEVEDO SF, KOLCHUGINA GK, BUTLER RW, CORBETT SM, HONEYCUTT EB, CRAYTOR MJ, RABER J: Abnormalities in parentally rated executive function in methamphetamine/polysubstance exposed children. Pharmacol Biochem Behav 98: 432-439, 2011.

RAMBOUSEK L, KAČER P, SYSLOVÁ K, BUMBA J, BUBENÍKOVÁ-VALEŠOVÁ V, ŠLAMBEROVÁ R: Sex differences in methamphetamine pharmacokinetics in adult rats and its transfer to pups through the placental membrane and breast milk. Drug Alcohol Depend 139: 138-144, 2014.

RICAURTE GA, SEIDEN LS, SCHUSTER CR: Further evidence that amphetamines produce long-lasting dopamine neurochemical deficits by destroying dopamine nerve-fibers. Brain Res 303: 359-364, 1984.

RICE D, BARONE S JR: Critical periods of vulnerability for the developing nervous system: evidence from humans and animal models. Environ Health Perspect 108 (Suppl 3): 511-533, 2000.

RICE OV, GATLEY SJ, SHEN J, HUEMMER CL, ROGOZ R, DEJESUS OT, VOLKOW ND, GIFFORD AN: Effects of endogenous neurotransmitters on the in vivo binding of dopamine and 5-HT radiotracers in mice. Neuropsychopharmacology 25: 679-689, 2001.

ROBINSON TE, BECKER JB: Enduring changes in brain and behavior produced by chronic amphetamine administration: a review and evaluation of animal models of amphetamine psychosis. Brain Res 396: 157-198, 1986.

ROBINSON TE, KOLB B: Structural plasticity associated with exposure to drugs of abuse. Neuropharmacology 47: 33-46, 2004.

ROUSSOTTE FF, BRAMEN JE, NUNEZ SC, QUANDT LC, SMITH L, O'CONNOR MJ, BOOKHEIMER SY, SOWELL ER: Abnormal brain activation during working memory in children with prenatal exposure to drugs of abuse: the effects of methamphetamine, alcohol, and polydrug exposure. Neuroimage 54: 3067-3075, 2011.

ROUSSOTTE FF, RUDIE JD, SMITH L, O'CONNOR MJ, BOOKHEIMER SY, NARR KL, SOWELL ER: Frontostriatal connectivity in children during working memory and the effects of prenatal methamphetamine, alcohol, and polydrug exposure. Dev Neurosci 34: 43-57, 2012.

SALAMONE JD, CORREA M: Motivational views of reinforcement: implications for understanding the behavioral functions of nucleus accumbens dopamine. Behav Brain Res 137: 3-25, 2002.

SCHAEFER TL, SKELTON MR, HERRING NR, GUDELSKY GA, VORHEES CV, WILLIAMS MT: Short- and long-term effects of (+)-methamphetamine and (+/-)-3,4-methylenedioxymethamphetamine on monoamine and corticosterone levels in the neonatal rat following multiple days of treatment. $J$ Neurochem 104: 1674-1685, 2008.

SCHANBERG SM, FIELD TM: Sensory deprivation stress and supplemental stimulation in the rat pup and preterm human neonate. Child Dev 58: 1431-1447, 1987.

SCHUTOVÁ B, HRUBÁ L, POMETLOVÁ M, DEYKUN K, ŠLAMBEROVÁ R: Impact of methamphetamine administered prenatally and in adulthood on cognitive functions of male rats tested in Morris water maze. Prague Med Rep 109: 62-70, 2008.

SCHUTOVÁ B, HRUBÁ L, POMETLOVÁ M, ŠLAMBEROVÁ R: Impact of prenatal and acute methamphetamine exposure on behaviour of adult male rats. Prague Med Rep 110: 67-78, 2009.

SEKINE Y, OUCHI Y, TAKEI N, YOSHIKAWA E, NAKAMURA K, FUTATSUBASHI M, OKADA H, MINABE Y, SUZUKI K, IWATA Y, TSUCHIYA KJ, TSUKADA H, IYO M, MORI N: Brain serotonin transporter density and aggression in abstinent methamphetamine abusers. Arch Gen Psychiatry 63: 90-100, 2006.

STEINER E, VILLEN T, HALLBERG M, RANE A: Amphetamine secretion in breast milk. Eur J Clin Pharmacol 27: 123-124, 1984.

ŠLAMBEROVÁ R, CHAROUSOVÁ P, POMETLOVÁ M: Maternal behavior is impaired by methamphetamine administered during pre-mating, gestation and lactation. Reprod Toxicol 20: 103-110, $2005 \mathrm{a}$.

ŠLAMBEROVÁ R, CHAROUSOVÁ P, POMETLOVÁ M: Methamphetamine administration during gestation impairs maternal behavior. Dev Psychobiol 46: 57-65, 2005b. 
ŠLAMBEROVÁ R, RILEY MA, VATHY I: Cross-generational effect of prenatal morphine exposure on neurobehavioral development of rat pups. Physiol Res 54: 655-660, 2005c.

ŠLAMBEROVÁ R, POMETLOVÁ M, CHAROUSOVÁ P: Postnatal development of rat pups is altered by prenatal methamphetamine exposure. Prog Neuropsychopharmacol Biol Psychiatry 30: 82-88, 2006.

ŠLAMBEROVÁ R, MACÚCHOVÁ E, NOHEJLOVÁ-DEYKUN K, SCHUTOVÁ B, HRUBÁ L, ROKYTA R: Gender differences in the effect of prenatal methamphetamine exposure and challenge dose of other drugs on behavior of adult rats. Physiol Res 62 (Suppl 1): S99-S108, 2013.

ŠLAMBEROVÁ R, VRAJOVÁ M, SCHUTOVÁ B, MERTLOVÁ M, MACÚCHOVÁ E, NOHEJLOVÁ K, HRUBÁ L, PUSKARČÍKOVÁ J, BUBENÍKOVÁ-VALEŠOVÁ V, YAMAMOTOVÁ A: Prenatal methamphetamine exposure induces long-lasting alterations in memory and development of NMDA receptors in the hippocampus. Physiol Res 63 (Suppl 4): S547-S558, 2014.

ŠLAMBEROVÁ R, POMETLOVÁ M, MACÚCHOVÁ E, NOHEJLOVÁ K, STUCHLÍK A, VALEŠ K: Do the effects of prenatal exposure and acute treatment of methamphetamine on anxiety vary depending on the animal model used? Behav Brain Res 292: 361-369, 2015.

VOLKOW ND, WANG GJ, FOWLER JS, THANOS P: Role of dopamine in drug abuse and addiction in human subjects: results from imaging studies. Mol Psychiatry 6 (Suppl 1): S3-S4, 2001.

VORHEES CV: Methods for detecting long-term CNS dysfunction after prenatal exposure to neurotoxins. Drug Chem Toxicol 20: 387-399, 1997.

WAGNER GC, RICAURTE GA, SEIDEN LS, SCHUSTER CR, MILLER RJ, WESTLEY J: Long-lasting depletions of striatal dopamine and loss of dopamine uptake sites following repeated administration of methamphetamine. Brain Res 181: 151-160, 1980.

WEISSMAN AD, CALDECOTT-HAZARD S: Developmental neurotoxicity to methamphetamines. Clin Exp Pharmacol Physiol 22: 372-374, 1995.

WILLIAMS MT, MORAN MS, VORHEES CV: Refining the critical period for methamphetamine-induced spatial deficits in the Morris water maze. Psychopharmacology (Berl) 168: 329-338, 2003a.

WILLIAMS MT, MORFORD LL, WOOD SL, WALLACE TL, FUKUMURA M, BROENING HW, VORHEES CV: Developmental D-methamphetamine treatment selectively induces spatial navigation impairments in reference memory in the Morris water maze while sparing working memory. Synapse 48: 138-148, $2003 \mathrm{~b}$.

WON L, BUBULA N, MCCOY H, HELLER A: Methamphetamine concentrations in fetal and maternal brain following prenatal exposure. Neurotoxicol Teratol 23: 349-354, 2001.

YAMAMOTOVÁ A, HRUBÁ L, SCHUTOVÁ B, ROKYTA R, ŠLAMBEROVÁ R: Perinatal effect of methamphetamine on nociception in adult Wistar rats. Int J Dev Neurosci 29: 85-92, 2011. 